\title{
GREEN SYNTHESIS, CHARACTERIZATION, AND IN VITRO ANTIMICROBIAL EFFICACY OF SILVER NANOPARTICLES SYNTHESIZED FROM TECTONA GRANDIS WOOD FLOUR
}

\author{
PINKI DANGI*, JANGIR OP \\ Department of Biotechnology, Maharaj Vinayak Global University, Jaipur, Rajasthan, India. Email: pinki.dangi@yahoo.com
}

Received: 03 August 2018, Revised and Accepted: 29 September 2018

\section{ABSTRACT}

Objective: Silver nanoparticles (AgNPs) are widely used as an antimicrobial agent. Due to the toxicity concerns related to the synthesis of the AgNPs, there is an urgent need of the novel green techniques to synthesis the AgNPs. In the light of the above, we had synthesized the AgNPs with the help of the Tectona grandis commonly known as teak wood.

Methods: The aqueous wood floor extract of the T. grandis was used as a reducing agent in the synthesis of the AgNPs. The NPs were synthesized and characterized using different techniques such as ultraviolet-visible spectroscopy, Dynamic light scattering (DLS), Transmission electron microscopy (TEM), and Scanning electron microscopy (SEM). The synthesized NPs were then evaluated for their antimicrobial efficacy against the Gramnegative and Gram-positive bacteria and antifungal activity. Further, in vitro antioxidant efficacy of the AgNPs was calculated using 2,2'-azino-bis(3ethylbenzothiazoline-6-sulphonic) acid and 2,2-diphenyl-1-picrylhydrazyl assay.

Results: From the above analyses, the formation of spherical NPs with an average size of 100 nm was confirmed. Minimum inhibitory concentration (MIC) and minimal biocidal concentration (MBC) of the AgNPs were calculated, MIC and MBC values ranged from 0.50 to $1.8 \mu \mathrm{g} / \mathrm{mL}$ and 0.91 to $3.6 \mu \mathrm{g} / \mathrm{mL}$, respectively.

Conclusion: The prepared NPs were found to be uniform in size with smooth topography. The antibacterial and antifungal efficacy of the NPs was found to be effective on the broad spectrum of microbes. The antioxidant activity of AgNPs was comparable to ascorbic acid.

Keywords: Tectona grandis, Silver nanoparticle, Green synthesis, Antibacterial, Antifungal.

(C) 2019 The Authors. Published by Innovare Academic Sciences Pvt Ltd. This is an open access article under the CC BY license (http://creativecommons. org/licenses/by/4. 0/) DOI: http://dx.doi.org/10.22159/ajpcr.2019.v12i1.28849

\section{INTRODUCTION}

Metal nanoparticles (NPs) are of great interest due to their special and unusual characteristics in comparison to their macroscopic counterpart. Such unusual and special nature of NPs extend their application in various fields such as medicine, biotechnology, microelectronics, optics, catalysis, information storage, and energy conversion [1,2]. Synthesis of NPs can be done using chemical and physical processes, but due to the use of immense amount of toxic chemicals and high temperature conditions, it has become necessary to find an alternative method. Therefore, researchers have now focused on biological systems for nanoparticle synthesis [3-7]. Synthesis of NPs by biological methods, using microorganisms, enzyme, and plant or plant extract, has been suggested as possible eco-friendly alternatives to chemical and physical methods. Biosynthesis of NPs by plant surpasses other biological methods by reducing the complicated process of maintaining cell culture [4,8-10]. The utilization of various plant materials for the synthesis of NPs is called as green synthesis as it does not involve any harmful chemicals. Water-soluble organics presented in the plant materials were mainly responsible for the reduction of silver ions to NPs of silver [3,4,11-13].

Metallic NPs are having a great potential in the field of antimicrobial research and other biomedical applications. Nobel metals such as silver and gold have been used for their antibacterial activities [4]. Green synthesis of the NPs of such metals may have significant applications in therapeutics. The green synthesis approach utilizes the waste material for the synthesis of AgNPs and involves no organic solvent, with no harsh conditions, thus making it reliable, simple, energy efficient, costeffective, self-sustaining, and environmental friendly $[8,14,15]$. These features serve to make the process as a green route for the synthesis of NPs.
Silver (Ag) is safe and known to have inhibitory and bactericidal effects and non-toxic to animal cell. Silver NPs (AgNPs) with high specific surface area and high fraction of surface atoms will possess high antimicrobial activity in comparison to bulk silver metal. Several studies have demonstrated that bactericidal properties of the AgNPs are strongly influenced by their shape, size, concentration, and colloidal state [16]. It has also been anticipated that there can be liberated of silver ions by the NPs, and these ions can interact with the thiol groups of many vital enzymes and inactivate them. The bacterial cells in contact with silver intake silver ions, which inhibit several functions in the cell and damage the cells. Staphylococcus is facultative anaerobic Gram-positive cocci which occur singly, in pairs, and irregular clusters. Staphylococcus aureus is non-motile, non-spore forming, catalase, and coagulase positive $[4,16,17]$.

Teak has been studied in great extent as extracts from different parts of teak and has shown antioxidant activities, anti-inflammatory, antipyretic, analgesic, wound healing, free radical scavenging properties, diuretic, and antibacterial properties [18]. Some studies have been published showing the efficiency of teak-based biosynthesis of NPs [19].

Wood flour - wood in a very fine particle form (consistency fairly equal to sand or sawdust) - is produced from selected dry wood residue by several types of grinders and sized by mechanical or air screening methods. Reineke [20] states that the term wood flour "is applied somewhat loosely to wood reduced to finely divided particles approximating those of cereal flours in size, appearance, and texture."

\section{METHODS}

Analytical grade silver nitrate, $99 \%\left(\mathrm{AgNO}_{3}\right)$, was obtained from SigmaAldrich, Germany. 2,2'-azinobis-(3-ethylbenzothiazoline-6-sulfonic 
acid) (ABTS), potassium persulfate, 1,1-diphenyl-2-picryl-hydrazil (DPPH) and resazurin dye were purchased from Sigma-Aldrich Chemical Co., St. Louis, USA. Phosphate-buffered saline (PBS), methanol, and all other media components and analytical reagents were purchased from Hi-Media Laboratories Pvt., Ltd. (Mumbai, India). Water used for the preparation of solutions was Grade II water (Milli- $Q$ grade from Elix 3, Millipore Corp., USA). All other chemicals used were of analytical grade and used as received without further purification. The standard strains of microorganisms Escherichia coli, Enterococcus faecalis, S. aureus, Aspergillus niger, and Candida albicans were used in the susceptibility test. These strains were obtained from IMTECH, Chandigarh, India.

\section{Preparation of wood flour extract}

Fresh, healthy, and disease-free Tectona grandis wood was collected from the Aravalli range of Rajasthan (India). The plant material was identified and authenticated by botanist in the Department of Botany, University of Rajasthan, Jaipur. The wood was washed repeatedly with deionized water to remove surface contaminants. The wood was cut and grinded to form fine powder/wood flour. A total of $25 \mathrm{~g}$ of wood flour were boiled with $200 \mathrm{~mL}$ of Milli- $\mathrm{Q}$ deionized water for $25 \mathrm{~min}$ before decantation. The crude extract, thus obtained, was filtered using Whatman No. 1 filter paper (Whatman Plc, Kent, UK).

\section{Synthesis of AgNPs}

In a typical one-step synthesis, AgNPs were prepared by the reduction of $\mathrm{AgNO}_{3}$. For reduction of $\mathrm{Ag}+\mathrm{ions}, 1 \mathrm{~mL}$ of wood flour extract was added to $9 \mathrm{~mL}$ of $1 \mathrm{mM}$ aqueous $\mathrm{AgNO}_{3}$ solution. The reaction mixture was allowed to stand at room temperature until the colorless solution converted into a reddish-brown color, indicating the formation of NPs. The reduction of pure Ag ions was monitored by measuring the ultraviolet (UV)-visible spectra of the solution, at different time periods.

Solution of biosynthesized AgNPs was treated with $\mathrm{NaCl}$ solution $(1 \% \mathrm{v} / \mathrm{v})$ to remove unreacted $\mathrm{Ag}$ ions. AgNPs in the solution were then centrifuged at $12,000 \times g$ for $30 \mathrm{~min}$, dried at $40^{\circ} \mathrm{C}$, and maintained at $4^{\circ} \mathrm{C}$. The dried mass of AgNPs was reconstituted in PBS or medium broth for further analysis.

\section{Characterization of silver NPs}

\section{UV-visible analysis}

The reduction of pure Ag+ ions in the presence of wood extract was monitored by visual inspection as well as by measuring the UV-visible spectrum at periodic intervals. UV-visible spectral analysis was done using UV-visible spectrophotometer (UV-1601 PC, Shimadzu dual-beam spectrophotometer) in wavelength ranging from 350 to $500 \mathrm{~nm}$.

\section{Scanning electron microscopy (SEM)}

The synthesized AgNPs from T. grandis extract were morphologically characterized using SEM (FEI Quanta 400 ESEM FEG, Philips ${ }^{\circledR}$, Netherlands). SEM slides were prepared by gold coating of the samples using sputter technique. Then, the samples were placed inside the SEM instrument at an accelerating voltage of $20 \mathrm{kV}$.

\section{Transmission electron microscopy (TEM)}

TEM was used for observing the size and shape distribution of synthesized AgNPs. Samples were prepared by drying a drop of AgNP solution on carbon-coated TEM copper grids followed by measurements on a JEOL Model 1200 EX TEM operated at an accelerating voltage of $200 \mathrm{kV}$ and analyzed with TECNAI G2 software.

\section{DLS and zeta potential analysis}

Dynamic light scattering (DLS), which is based on the laser diffraction method with multiple scattering techniques, was employed to study the average particle size of AgNPs. The AgNPs solution was filtered and centrifuged at $5000 \mathrm{rpm}$ for $15 \mathrm{~min}$ at $25^{\circ} \mathrm{C}$ and the supernatant was collected. The supernatant was diluted for $4-5$ times, and then, the particle distribution in liquid was studied in a computerized controlled particle size analyzer (ZETAsizer Nanoseries, Malvern Instrument Nano Zs).

\section{Antimicrobial activity study}

The antimicrobial activity was studied against two Gram-positive bacteria (S. aureus and E. faecalis), one Gram-negative bacteria (E. coli), filamentous algae (A. niger), and yeast (C. albicans).

\section{Determination of minimum inhibitory concentration (MIC)}

The antimicrobial activity was determined using standard broth dilution methods in accordance to Clinical and Laboratory Standards Institute guidelines [21-23] (M07-A9 guideline for bacteria; M27-A3 guideline for yeasts; and M38-A2 guideline for filamentous fungi) with slight modifications [24,25]. Mueller-Hinton broth (MHB) was used as medium.

NPs were dissolved in MHB media at twice the final test concentration with $\mathrm{pH}$ adjusted at 7.2-7.6. $100 \mu \mathrm{L}$ of the NP-MHB broth was dispensed in each well of Column 1, while Columns 2-10 contained $50 \mu \mathrm{L}$ of MHB broth only. Column 11 contained $100 \mu \mathrm{L}$ of diluted standardized inoculum, and Column 12 contained $100 \mu \mathrm{L}$ of the medium broth (as a control to monitor sterility). A multichannel pipette was then used to transfer and NP-MHB from Column 1 to 10 , resulting in $50 \mu \mathrm{L}$ per well. The concentrations of the different NPs achieved through double serial dilutions from Columns 1 to 10 were from $100 \mu \mathrm{g} / \mathrm{ml}$ to $0.195 \mu \mathrm{g} / \mathrm{ml}$.

The standardized microorganism suspension was then diluted by 1:100 in MHB broth. $50 \mu \mathrm{L}$ of the microbial cells suspended in MHB was then added to all wells containing NPs and to the control wells, resulting in approximately $5 \times 10^{5}$ colony-forming unit $(\mathrm{CFU}) / \mathrm{mL}$ (bacterial concentration) and $0.5-2.5 \times 10^{3} \mathrm{CFU} / \mathrm{mL}$ (yeast/fungi concentration). Plates were incubated at $37^{\circ} \mathrm{C}$ for $18 \mathrm{~h}$ (bacteria) and $48 \mathrm{~h}$ (yeasts and fungi) after incubation, $20 \mu \mathrm{l}$ of resazurin dye $(0.02 \%)$ was added and allowed $3 \mathrm{~h}$ incubation.

Viable microbes cause the appearance of pink coloration. The concentration that did not show the appearance of pink solution (remain blue) was considered as the inhibition concentration and the smallest one was noted as the MIC. The MIC is thus the lowest concentration of antimicrobial agent that completely visually inhibits $99 \%$ growth of the bacteria. The MIC measurement was done in triplicate to confirm the value of MIC for each tested organism.

\section{Determination of minimal biocidal concentration (MBC)}

After MIC determination, aliquots of $50 \mu \mathrm{l}$ from all tubes in which no visible microbial growth was observed were seeded in freshly prepared MHB plates and reincubated for $24-48 \mathrm{~h}$ at $37^{\circ} \mathrm{C}$. After this reincubation, resazurin dye was introduced in each well and all the concentrations that did not present color change were considered as the bactericidal concentration, and the smallest one was noted as MBC. The MBC end point is defined as the lowest concentration of antibacterial agent that kills $100 \%$ of the initial bacterial population. The assay was repeated thrice. Gentamicin and amphotericin B served as positive control for bacteria and fungi, respectively.

\section{Antioxidant assay \\ ABTS $^{+}$assay}

The colorimetric analysis of ABTS free radical scavenging activity was conducted [26-28]. Briefly, ABTS $\bullet^{+}$, monocationic radical was produced by oxidation of $7 \mathrm{mM}$ ABTS with $2.45 \mathrm{mM}$ potassium persulfate when stored in dark for $16 \mathrm{~h}$. For the assay, the ABTS solution was diluted to provide an absorbance of 0.70 at $732 \mathrm{~nm}$ in water. Then, $2.9 \mathrm{ml}$ of ABTS solution prepared in MQ water was mixed with $0.1 \mathrm{ml}$ of NP solution at different concentrations $(10-80 \mu \mathrm{g} / \mathrm{ml})$ in water. The kinetics of change in color was monitored up to $30 \mathrm{~min}$. The scavenging capability of ABTS $\bullet^{+}$was calculated using the following equation: 
ABTS scavenging effect $\%=\left[\left(A_{a b t s}-A_{s}\right) / A_{a b t s}\right] \times 100$

Where, $A_{a b t s}$ is the initial concentration of the ABTS and $A_{s}$ is the absorbance of the remaining concentration of ABTS in the presence of sample solution.

\section{$D P P H \bullet$ radical scavenging assay}

Antioxidant potential of AgNPs against DPPH was determined using the method described [29]. DPPH is a stable radical in solution that appears purple colored, absorbing at $515 \mathrm{~nm}$ in methanol. This assay is based on the principle that DPPH• on accepting a hydrogen $(\mathrm{H})$ atom from the scavenger molecule, that is, antioxidant, results into reduction of $\mathrm{DPPH} \bullet$, the purple color changes to yellow with concomitant decrease in absorbance at $515 \mathrm{~nm}$. Briefly, $2.9 \mathrm{ml}$ of $60 \mathrm{mM}$ DPPH solution was mixed with $0.1 \mathrm{ml}$ of AgNPs solution at different concentrations $(10-80 \mu \mathrm{g} / \mathrm{mL})$ in water kept at room temperature for $30 \mathrm{~min}$. The decrease in absorbance was monitored at $515 \mathrm{~nm}$. DPPH $\bullet$ radical scavenging capacity was calculated using following equation.

DPPH scavenging effect $(\%)=\left[\left(A_{d p p h}-A_{s}\right) / A_{d p p h}\right] \times 100$

Where, $A_{d p p h}$ and $A_{s}$ correspond to the absorbance at $515 \mathrm{~nm}$ of the radical (DPPH•) in the absence and presence of sample, respectively.

\section{Statistical analysis}

The data are expressed in as mean \pm standard deviation. The samples in each assay were tested at least in triplicate. The data analysis was done using one-way ANOVA with Dunnett's post-test with GraphPad Prism version 5.00 for Windows (GraphPad Software, San Diego, California, USA). The data were considered statistically significantly different if $\mathrm{p}<0.05$.

\section{RESULTS}

\section{Preparation of wood flour extract}

The wood flour extract was obtained by "decoction." The yellowishbrown aqueous extract was strained and refrigerated until further use.

\section{Synthesis of AgNPs}

The wood flour extract was used for the synthesis of AgNPs by taking the wood flour and adding $1 \mathrm{mM}$ silver nitrate solution for 1:9 ratio and after $6 \mathrm{~h}$ color changed to brownish-red. The final NPs were welldispersed solution (Fig. 1) that was subsequently confirmed by DLS. Aqueous solution of AgNPs has brownish-red color, which may be due to surface plasmon resonance.

\section{Characterization of AgNPs}

\section{UV-visible analysis}

The reaction mixture of wood flour extracts with aqueous solution of silver nitrate started to change its color from yellowish-brown to reddish-brown. It indicates the formation of AgNPs with the reduction of silver ions. UV-visible spectral analysis was done using UV-visible spectrophotometer. UV-visible spectrograph of AgNPs has been recorded as a function of time. Absorption spectra of AgNPs formed in the reaction media at $6 \mathrm{~h}$ have absorbance peak between 420 and $430 \mathrm{~nm}$, broadening of peak indicated that the particles are polydispersed (Fig. 1).

\section{SEM}

The images obtained from SEM analysis are shown in Fig. 2. The shape of AgNPs appears to be spherical to cubical with polydispersed in nature. The size ranges from $50 \mathrm{~nm}$ to $200 \mathrm{~nm}$.

\section{TEM}

TEM analysis was performed on the prepared AgNP using TEM Morgagni 268D. The TEM images obtained are presented in Fig. 3. The TEM images reveal the size of synthesized AgNPs in the range of 30-50 nm which are spherical in shape.

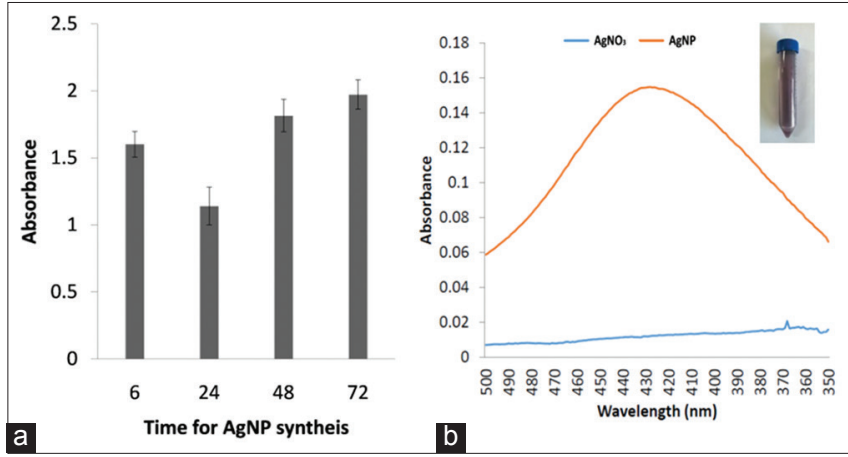

Fig. 1: (a) The bar graph represents the absorption at $\lambda \max$ $(426 \mathrm{~nm})$ against different time points after incubation of the aqueous extract with $\mathrm{AgNO}_{3}$ solution. (b) The spectrum obtained from synthesized nanoparticles with synthesized AgNPs in inset

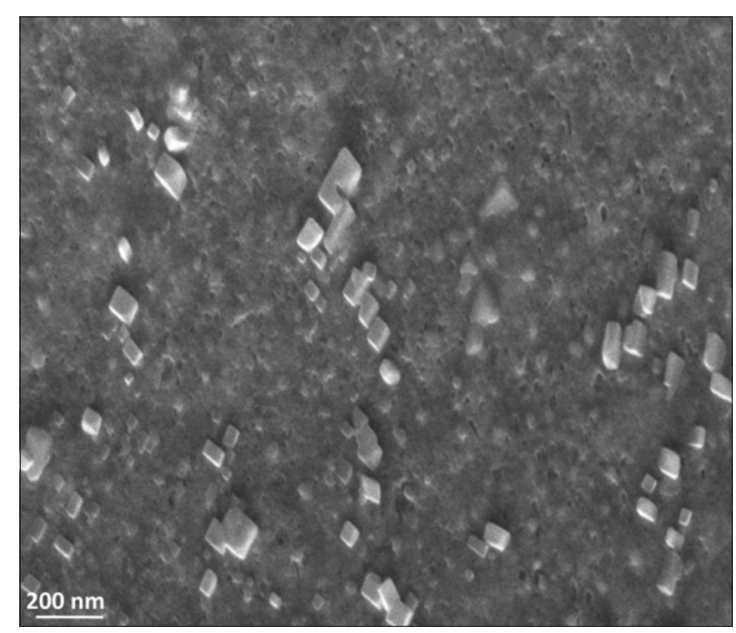

Fig. 2: AgNPs at a resolution of $200 \mathrm{~nm}$ showing spherical and cubical nanoparticles using scanning electron microscopy

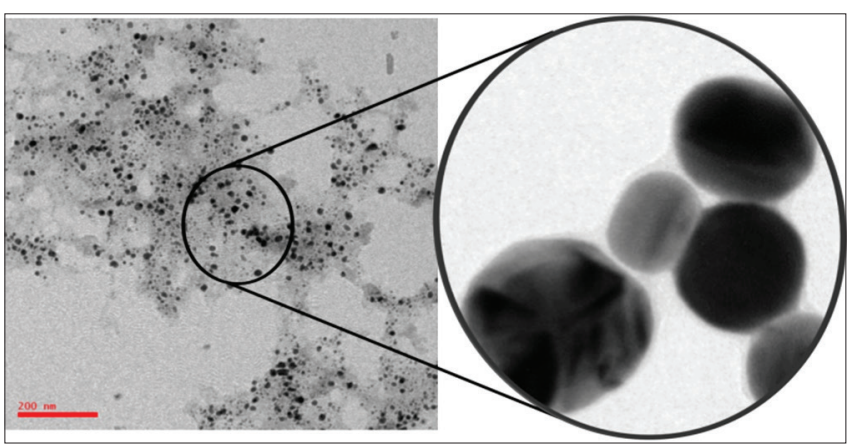

Fig. 3: AgNPs at a resolution of $200 \mathrm{~nm}$ showing spherical nanoparticles using transmission electron microscopy

\section{DLS and zeta potential analysis}

DLS studies were performed on the prepared AgNP, show that the average diameter of the particles was found to be $190.8 \mathrm{~nm}$ with a polydispersity index of 0.261 . The results obtained are shown in Fig. 4a.

Zeta potential analysis was performed on AgNPs using ZETAsizer Nanoseries, Malvern Instrument Nano Zs, the results for zeta potential are shown in Fig. 3b. The results indicate that the AgNPs are small in size for which they are energetically very unstable. Therefore, the particles undergo agglomeration/aggregation to stabilize themselves. Hence, the presence of potential charges on the surface of the NPs 
makes them stable. Peak observed in Fig. 4b represents that the NPs have charge of $-3.68(\mathrm{mV})$, indicating the NPs are very stable in nature.

\section{Antimicrobial activity}

\section{Minimum inhibitory concentration}

The AgNPs synthesized from T. grandis wood flour were observed to have high antimicrobial activity as compared to the aqueous plant extract. The antimicrobial activity when compared to the standard antibiotics, that is, gentamicin and amphotericin B had insignificant $(p>0.05)$ differences, for both antibacterial and antifungal activity, respectively. The MIC of AgNPs against Gram-positive bacteria was $0.52 \mu \mathrm{g} / \mathrm{ml}$ and $0.91 \mu \mathrm{g} / \mathrm{ml}$ for $S$. aureus and E. faecalis compared to gentamicin that showed MIC at $0.32 \mu \mathrm{g} / \mathrm{ml}$ and $0.45 \mu \mathrm{g} / \mathrm{ml}$, respectively. For gram negative bacteria (E.coli), MIC was $0.65 \mu \mathrm{g} / \mathrm{ml}$ compared to $0.52 \mu \mathrm{g} / \mathrm{ml}$ for gentamicin. The MIC for antifungal activity was $1.3 \mu \mathrm{g} / \mathrm{ml}$ and $1.8 \mu \mathrm{g} / \mathrm{ml}$ for $A$. niger and C. albicans compared to 0.91 and 1.04 for amphotericin $B$, respectively $(p>0.05)$. The MIC by aqueous extract was significantly higher $(p<0.05)$ and ranged from 5.2 to $8.3 \mu \mathrm{g} / \mathrm{ml}$.

\section{Minimum biocidal concentration}

The MBC for antibacterial effect of AgNPs against S. aureus and E. faecalis was at the concentration of 0.91 and $1.04 \mu \mathrm{g} / \mathrm{ml}$, respectively, and for gram negative bacteria (E.coli) was $0.91 \mu \mathrm{g} / \mathrm{ml}$. The MBC for antifungal effect were 3.6 and $3.3 \mu \mathrm{g} / \mathrm{ml}$ for A. niger and C. albicans, respectively. The MBC for aqueous extract was significantly higher $(\mathrm{p}<0.05)$ and ranged from 9.3 to $16.6 \mu \mathrm{g} / \mathrm{ml}$. The MIC and MBC against various organisms are represented in Fig. 5.

\section{Antioxidant assay \\ ABTS assay}

Antioxidant assay was performed using various concentrations (10, 20, 40,60, and $80 \mu \mathrm{g} / \mathrm{ml}$ ) of AgNP compared to extract and standard antioxidant, that is, ascorbic acid. The antioxidant/free radical scavenging capacity was found to increase with the concentration of sample. Antioxidant activity of ascorbic acid approximately saturated at $60-80 \mu \mathrm{g} / \mathrm{ml}$, while increase in antioxidant activity of AgNP was significantly higher than corresponding concentrations of plant extract $(\mathrm{p}<0.5)$.

\section{DPPH• assay}

Similar to ABTS assay, the free radical scavenging ability/antioxidant capacity of AgNP was higher than corresponding concentrations of wood flour extract $(\mathrm{p}<0.05)$. The DPPH $\bullet$ scavenging capacity of AgNP at $80 \mu \mathrm{g} / \mathrm{mL}$ was similar to ascorbic acid. The IC $_{50}$ values are represented in Table 1. Antioxidant activity of aqueous plant extract, AgNP, and ascorbic acid at various concentrations using ABTS and DPPH assay is represented in Fig. 6.

\section{DISCUSSION}

The green synthesis of metal NPs has recently gained popularity in research due to their cost-effective and simple method of preparation. In addition, the biologically mediated synthesis is dependable and environmentally-friendly approaches preventing from the hazardous effects of chemical-mediated processes.

The biological synthesis of NPs depends on the solvent, the reducing agent, and the non-toxic material. The green synthesis

Table 1: $\mathrm{IC}_{50}$ values for ABTS assay and DPPH assay for aqueous plant extract, AgNPs, and ascorbic acid (standard antioxidant)

\begin{tabular}{lll}
\hline Sample & $\begin{array}{l}\text { IC }_{\mathbf{5 0}} \text { ABTS } \\
(\boldsymbol{\mu g} / \mathbf{m L})\end{array}$ & $\begin{array}{l}\text { IC }_{\mathbf{5 0}} \mathbf{D P P H} \\
(\boldsymbol{\mu g} / \mathbf{m L})\end{array}$ \\
\hline Aqueous plant extract & 71.87304 & 47.90982 \\
AgNP & 41.44613 & 35.9555 \\
Ascorbic acid & 29.24459 & 32.34388 \\
\hline
\end{tabular}

ABTS: 2,2'-Azinobis-(3-ethylbenzothiazoline-6-sulfonic acid), DPPH: 1,1-Diphenyl-2-picrylhydrazyl

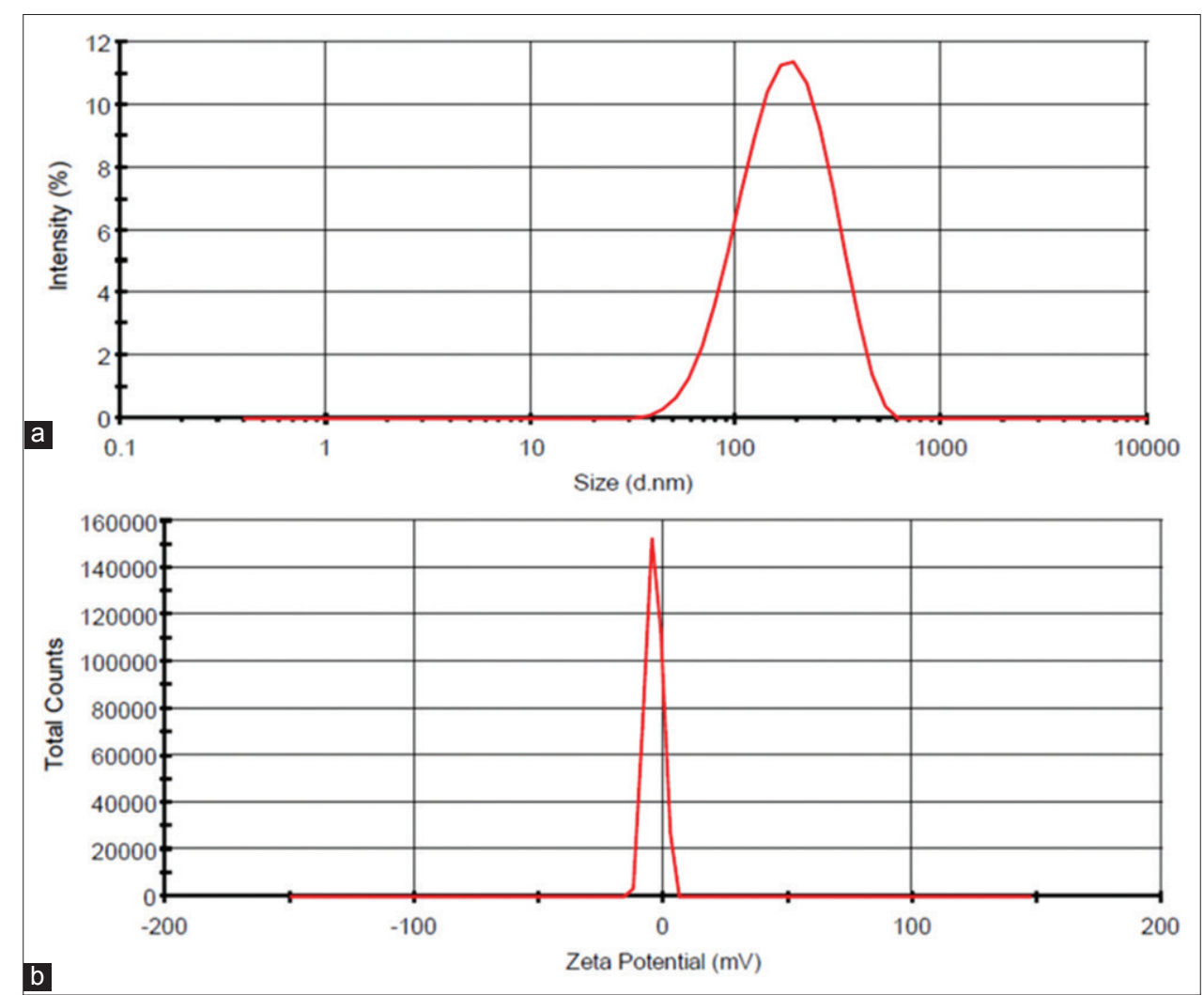

Fig. 4: (a) The figure represents the graph obtained from dynamic light scattering showing size of NPs at $190.8 \mathrm{~nm}$. (b) The figure represents the graph obtained for zeta potential (mV) 


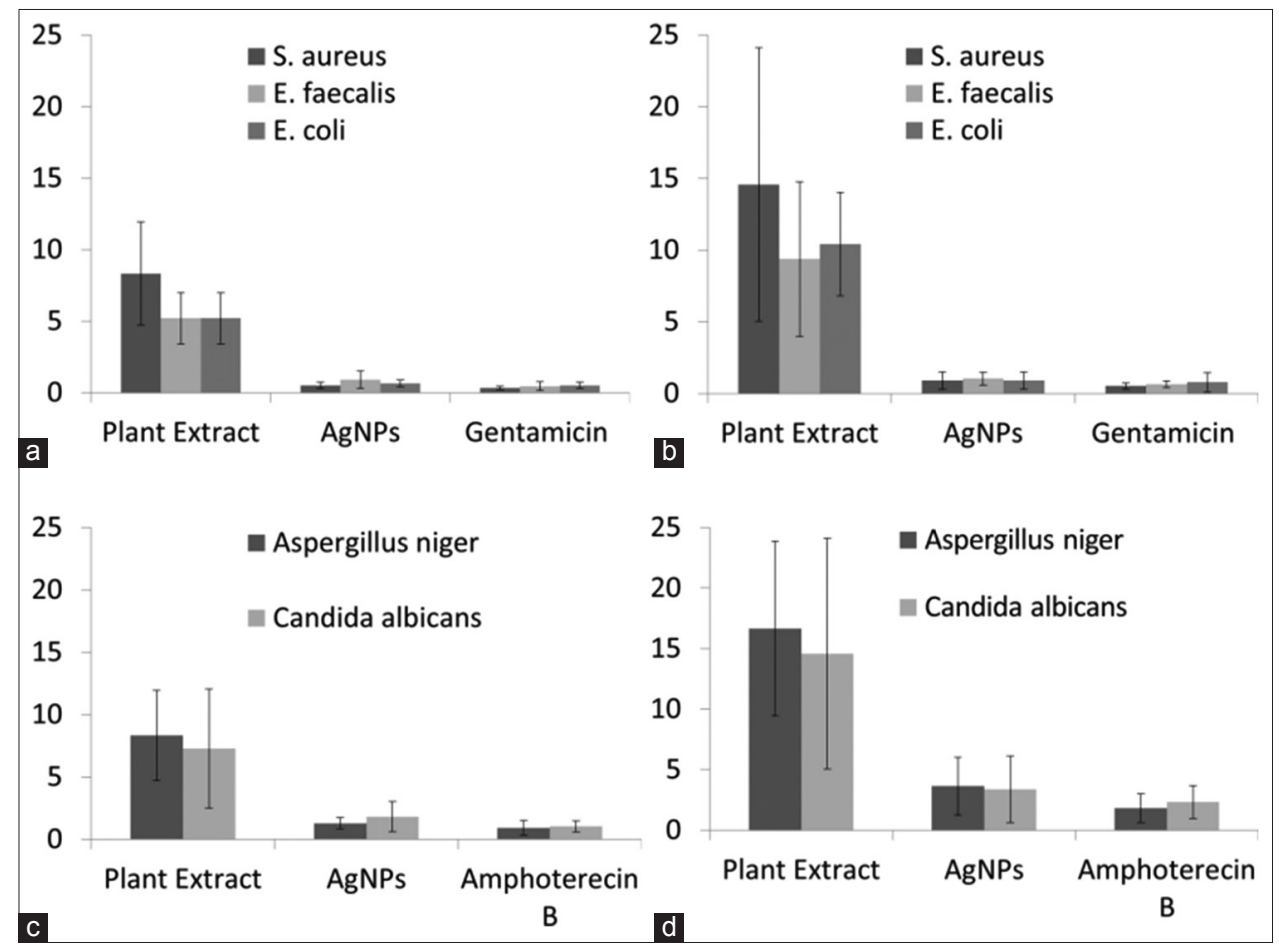

Fig. 5: The minimum inhibitory concentration (MIC) and minimal biocidal concentration (MBC) against various organisms are represented. (a) MIC in bacteria, (b) MIC in fungi, (c) MBC in bacteria, (d) MBC in fungi

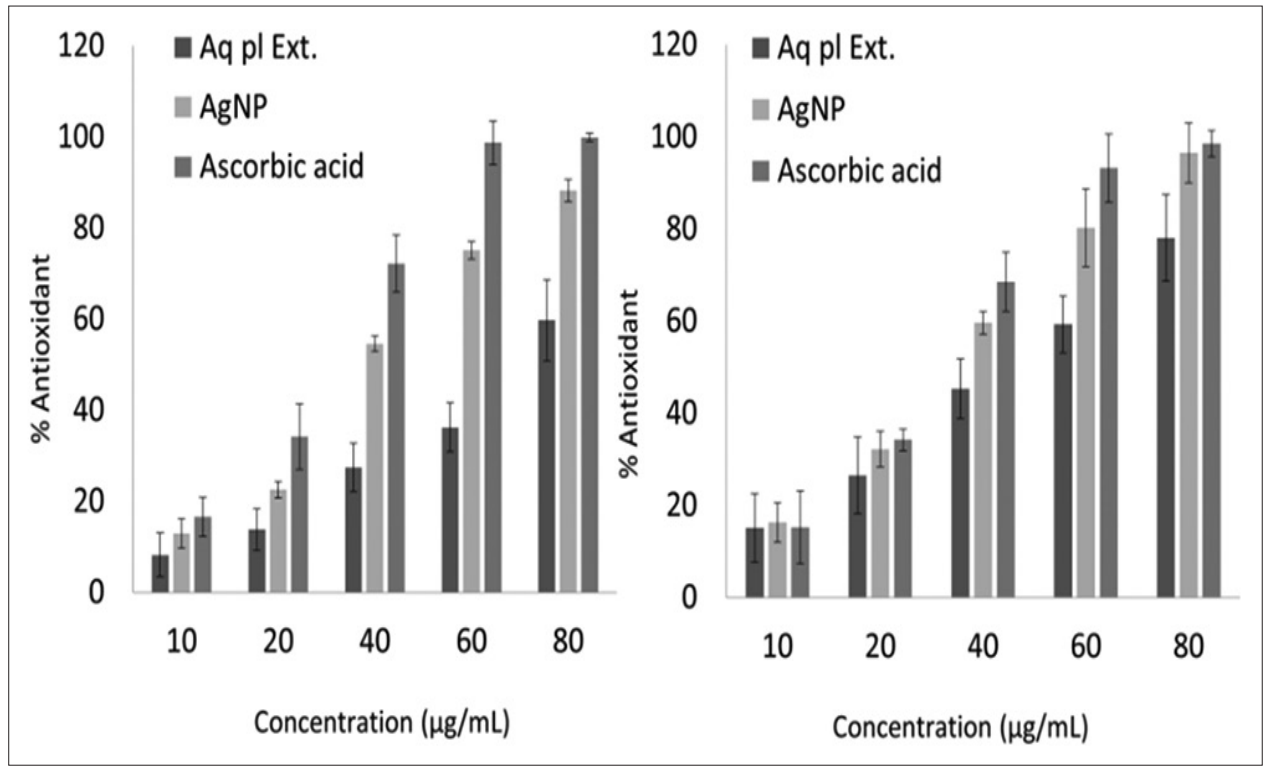

Fig. 6: Antioxidant activity of aqueous plant extract, AgNP, and ascorbic acid at various concentrations using 2,2'-azinobis-(3ethylbenzothiazoline-6-sulfonic acid) and 1,1-diphenyl-2-picrylhydrazyl assay

utilizes the potent active principals of plant extract, for example, amino acids, proteins, or secondary metabolites as flavonoids, terpenoids, alkaloids, etc., for the prevention of particle aggregation. Furthermore, the active ingredients in plant extracts act as biological reducing agents, producing eco-friendly, and pollution-free metal NPs. Thus, biological methods seem to provide controlled particle size and shape, which is an important factor for various biomedical applications [30].

In the present research, green synthesis of AgNPs using wood flour extract from T. grandis was successfully achieved. This technique revealed that the T. grandis wood flour extract can be used as an effective stabilizing reducing and capping agent for the synthesis of AgNPs. The
AgNPs synthesized were characterized and found to be polydispersed with spherical and cubical shape with size ranging from 30 to $190 \mathrm{~nm}$. The charge on NPs helps to get stabilized NPs.

In vitro analysis of antibacterial activity showed good antibacterial activity against both Gram-positive (S. aureus and E. faecalis) and Gramnegative (E. coli) bacteria. Simultaneously, the AgNPs were found to possess good antifungal activity against filamentous fungi (A. niger) and yeast (C. albicans).

In addition, the AgNP as well as the aqueous plant extract were found to have good antioxidant capacity represented by ABTS and DPPH radical scavenging assay. 


\section{CONCLUSION}

The AgNPs were synthesized using T. grandis wood flour extract and characterized successfully. This method of reduction utilized here is very simple, easy to perform, inexpensive, eco-friendly, and superior substitute to chemical synthesis. The finally fashioned AgNPs were highly stable and possess strong antibacterial and antioxidant activity.

\section{AUTHORS' CONTRIBUTION}

Pinki Dangi performed experiments, data collection, analysis, and manuscript writing; OP Jangir guided supervised experiments and reviewed manuscript. Manuscript was approved by all authors.

\section{CONFLICTS OF INTEREST}

The authors declare that they have no conflicts of interest.

\section{REFERENCES}

1. Zhang HM, Zhang Y. Melatonin: A well-documented antioxidant with conditional pro-oxidant actions. J Pineal Res 2014;57:131-46.

2. Rahi DK, Parmar AS, Tiwari V. Biosynthesis of silver nanoparticles from fungal root endophytes of sida acuta plant and evaluation of their antibacterial and antibiotic enhancing activity. Int J Pharm Pharm Sci 2014;6:160-6.

3. He Y, Du Z, Lv H, Jia Q, Tang Z, Zheng X, et al. Green synthesis of silver nanoparticles by Chrysanthemum morifolium Ramat. Extract and their application in clinical ultrasound gel. Int J Nanomed 2013;8:1809-15.

4. Saha S, John N, Jincy V, Khanum SN, Ganesh. Biological synthesis, characterization and application of silver nano particles - A review. Int J Pharm Appl 2013;4:976-2639.

5. Rajendran R, Ganesan N, Balu SK, Alagar S, Thandavamoorthy P, Thiruvengadam D. Green synthesis, characterization, antimicrobial and cytotoxic effects of silver nanoparticles using Origanum heracleoticum L. Leaf extract. Int J Pharm Pharm Sci 2015;7:288-93.

6. Patil S, Sivaraj R, Rajiv P, Venckatesh R, Seenivasan R. Green synthesis of silver nanoparticle from leaf extract of Aegle marmelos and evaluation of its antibacterial activity. Int $\mathrm{J}$ Pharm Pharm Sci 2015;7:169-73.

7. Murugesan S, Bhuvaneswari S, Sivamurugan V. Green synthesis, characterization of silver nanoparticles of a marine red alga spyridia fusiformis and their antibacterial activity. Int $\mathrm{J}$ Pharm Pharm Sci 2017;9:192-7.

8. Kaler A, Jain S, Banerjee UC. Green and rapid synthesis of anticancerous silver nanoparticles by Saccharomyces boulardii and insight into mechanism of nanoparticle synthesis. Biomed Res Int 2013;2013:1-8.

9. Singh G, Babele PK, Shahi SK, Sinha RP, Tyagi MB, Kumar A. Green synthesis of silver nanoparticles using cell extracts of Anabaena doliolum and screening of its antibacterial and antitumor activity. J Microbiol Biotechnol 2014;24:1354-67.

10. Narayanan KB, Sakthivel N. Biological synthesis of metal nanoparticles by microbes. Adv Colloid Interface Sci 2010;156:1-13.

11. Devadiga A, Vidya SM, Saidutta MB. Timber industry waste-teak (Tectona grandis Linn.) leaf extract mediated synthesis of antibacterial silver nanoparticles. Int Nano Lett 2015;5. Doi:10.1007/s40089-0150157-4.

12. Okafor F, Janen A, Kukhtareva T, Edwards V, Curley M. Green synthesis of silver nanoparticles, their characterization, application and antibacterial activity. Int $\mathrm{J}$ Environ Res Public Health 2013;10:5221-38.

13. Singh K, Panghal M, Kadyan S, Chaudhary U, Yadav JP. Green silver nanoparticles of Phyllanthus amarus: As an antibacterial agent against multi drug resistant clinical isolates of Pseudomonas aeruginosa. J Nanobiotechnol 2014;12:40.

14. Atta A, Al-Lohedan H, Ezzat A. Synthesis of silver nanoparticles by green method stabilized to synthetic human stomach fluid. Molecules 2014;19:6737-53

15. Anbarasu A, Karnan P, Deepa N, Usha R. Carica papaya mediated green synthesized silver nanoparticles. Int J Curr Pharm Res 2010;10:15-20.

16. Jeevan P, Ramya K, Rena AE. Extracellular biosynthesis of silver nanoparticles by culture supernatant of Pseudomonas aeruginosa. Indian J Biotechnol 2012;11:72-6.

17. Dakal TC, Kumar A, Majumdar RS, Yadav V. Mechanistic basis of antimicrobial actions of silver nanoparticles. Front Microbiol 2016;7:1831.

18. Vyas P, Yadav DK, Khandelwal P. Tectona grandis (teak) - A review on its phytochemical and therapeutic potential. Nat Prod Res 2018;2018:1-17.

19. Devadiga A, Shetty KV, Saidutta MB. Timber industry waste-teak (Tectona grandis Linn.) leaf extract mediated synthesis of antibacterial silver nanoparticles. Int Nano Lett 2015;5:205-14.

20. Reineke LH. Lester H 1900-, (U.S.) FPL. Wood Flour; 1961.

21. CLSI. M07-A10 Methods for Dilution Antimicrobial Susceptibility Tests for Bacteria That Grow Aerobically; Approved Standard. $10^{\text {th }}$ ed. Wayne, PA: Clinical and Laboratory Standards Institute; 2015.

22. CLSI. M27-A3 Reference Method for Broth Dilution Antifungal Susceptibility Testing of Yeasts; Approved Standard. $3^{\text {rd }}$ ed. Wayne, PA: Clinical and Laboratory Standards Institute; 2008.

23. CLSI. M38-A2 Reference Method for Broth Dilution Antifungal Susceptibility Testing of Filamentous Fungi; Approved Standard. $2^{\text {nd }}$ ed. Wayne, PA: Clinical and Laboratory Standards Institute; 2008.

24. Elshikh M, Ahmed S, Funston S, Dunlop P, McGaw M, Marchant R, et al. Resazurin-based 96-well plate microdilution method for the determination of minimum inhibitory concentration of biosurfactants. Biotechnol Lett 2016;38:1015-9.

25. Tye KY, Gan SY, Lim SH, Tan SE, Chen CA, Phang SM. Comparison of visual observation and emission intensity of resazurin for antimicrobial properties of hexane, dichloromethane, methanol and water extracts from a brown alga, Turbinaria ornata. Cogent Biol 2016;2. Doi:10.108 0/23312025.2016.1225877.

26. Kumar A, Selvan TG, Tripathi AM, Choudhary S, Khan S, Adhikari JS, et al. Sesamol attenuates genotoxicity in bone marrow cells of wholebody $\gamma$-irradiated mice. Mutagenesis 2015;30:651-61.

27. Kumar A, Choudhary S, Adhikari JS, Chaudhury NK. Sesamol ameliorates radiation induced DNA damage in hematopoietic system of whole body $\gamma$-irradiated mice. Environ Mol Mutagen 2017. Doi:10.1002/em.22118.

28. Alok A, Adhikari JS, Chaudhury NK. Radioprotective role of clinical drug diclofenac sodium. Mutat Res 2013;755:156-62.

29. Mishra K, Ojha H, Chaudhury NK. Estimation of antiradical properties of antioxidants using DPPH-assay: A critical review and results. Food Chem 2012;130:1036-43.

30. Zhang XF, Liu ZG, Shen W, Gurunathan S. Silver nanoparticles: Synthesis, characterization, properties, applications, and therapeutic approaches. Int J Mol Sci 2016;17. Doi:10.3390/ijms17091534. 